\title{
Burden of Paediatric Sepsis in a Tertiary Centre from a Developing Country
}

\author{
O Olugbuyi ${ }^{1}, \mathrm{~K} \mathrm{Swaby}^{1}$, P Roberts $^{1}, \mathrm{C} \mathrm{Christie}^{1}, \mathrm{~N}_{\text {Kissoon }}^{2}$
}

\begin{abstract}
Background: Sepsis causes significant paediatric morbidity and mortality in developing countries. This paper describes the outcome of paediatric sepsis in the University Hospital of the West Indies (UHWI), Jamaica, using administrative data from hospital records from 2010 to 2014.

Objective: To provide baseline data on the burden and outcome of paediatric sepsis in a tertiary institution in Jamaica between 2010 and 2014 so as to embark on initiatives to build capacity to provide care in order to decrease the burden and improve the outcomes from sepsis in children.

Methods: Data were abstracted from electronic discharge summaries of children hospitalized at the UHWI, a tertiary centre that accepts referrals for newborns and children with complex disorders. The medical records of children aged 0-16 years who were hospitalized with a diagnosis of sepsis, septicaemia and neonatal sepsis were reviewed, using the World Health Organization's International Classification of Diseases, $10^{\text {th }}$ Revision (ICD-10). Demographic and outcome data were extracted.

Results: Among 7011 children aged 0-16 years who were admitted, sepsis accounted for 801 hospitalizations in 782 children with a male to female ratio of 1.27 to 1 . Neonates comprised $86 \%(n=691)$, of which $36.2 \%(n=250)$ were preterm. The median duration of hospitalization was 10 days (range: 0-366 days; interquartile range: 7-19 days). The sepsis-attributable mortality rate was $10.1 \%(n=70)$ in neonates and was higher in preterm versus term neonates (18.4\%, $n=46 / 250$ versus $6.0 \%, n=26 / 434$, respectively). The annual crude mortality rate for paediatric sepsis was $9-11 \%$ (12 per 1000 paediatric hospitalizations).

Conclusion: Sepsis accounted for a high number of admissions and consumed significant resources as evidenced by the long duration of hospitalization. The mortality rate for paediatric sepsis was high, especially in newborns. Targeted interventions are needed to reduce the sepsis-attributable burden and improve outcomes established by the Global Sepsis Alliance and United Nations'Sustainable Development Goals.
\end{abstract}

Keywords: Children, intensive care unit, Jamaica, sepsis

From: ${ }^{1}$ Department of Child and Adolescent Health, The University of the West Indies, Mona, Kingston, Jamaica, West Indies and ${ }^{2}$ British Columbia Children's Hospital and Sunny Hill Health Centre for Children, Department of Pediatrics and Emergency Medicine, University of British Columbia, Vancouver, Canada.
Correspondence: Dr O Olugbuyi, Department of Child and Adolescent Health, The University of the West Indies, Mona, Kingston 7, Jamaica, West Indies. Email: oluwayomi.olugbuyi@ uwimona.edu.jm 


\title{
Carga de sepsis pediátrica en un centro terciario de un país en desarrollo
}

\author{
O Olugbuyi ${ }^{1}, \mathrm{~K} \mathrm{Swaby}^{1}, \mathrm{P}^{\text {Roberts }}{ }^{1}, \mathrm{C}_{\text {Christie }}{ }^{1}, \mathrm{~N} \mathrm{Kissoon}^{2}$
}

\begin{abstract}
RESUMEN
Anteceentes: La sepsis causa morbilidad y mortalidad pediátricas significativas en los países en desarrollo. Este artículo describe el resultado de la sepsis pediátrica en el Hospital Universitario de West Indies (HUWI), Jamaica, utilizando datos administrativos de registros hospitalarios de 2010 a 2014.

Objetivo: Proporcionar datos de referencia sobre la carga y el resultado de la sepsis pediátrica en una institución terciaria en Jamaica entre 2010 y 2014, a fin de emprender iniciativas para aumentar la capacidad de prestar atención a disminuir la carga y mejorar los resultados de la sepsis en los niños.

Métodos: Se obtuvieron datos de resúmenes de descargas electrónicas de niños hospitalizados en el HUWI, un centro terciario que acepta remisiones de recién nacidos y niños con trastornos complejos. Se realizó una revisión de las historias clínicas de niños de 0 a 16 años de edad que fueron hospitalizados con un diagnóstico de sepsis, septicemia y sepsis neonatal, utilizando la Clasificación Internacional de Enfermedades de la Organización Mundial de la Salud, $10^{\text {th }}$ Revisión (ICD-10). Se obtuvieron datos en relación con la demografía y los resultados clínicos. Resultados: Entre los 7011 niños de 0 a 16 años de edad que fueron ingresados, la sepsis fue la causa de 801 hospitalizaciones en 782 niños, en una proporción varón-mujer de 1.27 a 1. Los neonatos abarcaron el $86 \%(n=691)$, el $36.2 \%$ de los cuales $(n=250)$ eran prematuros. La duración promedio de la hospitalización fue de 10 días (rango: 0-366 dias; rango intercuartil: 7-19 dias). La tasa de mortalidad atribuible a la sepsis fue de $10.1 \%(n=70)$ en los neonatos, y fue mayor entre los prematuros en comparación con los neonatos a término $(18.4 \%, n=$ $46 / 250$ frente a $6.0 \%, n=26 / 434$, respectivamente). La tasa de mortalidad bruta anual para la sepsis pediátrica fue de 9 a 11\% (12 por cada 1000 hospitalizaciones pediátricas).

Conclusión: La sepsis representó un elevado número de ingresos y consumió recursos significativos como se evidenció en la larga duración de la hospitalización. La tasa de mortalidad por sepsis pediátrica fue alta, especialmente en recién nacidos. Se necesitan intervenciones especificas para reducir la carga atribuible a la sepsis y mejorar los resultados establecidos por la Alianza Mundial contra la Sepsis y los Objetivos del Desarrollo Sostenible de las Naciones Unidas.
\end{abstract}

Palabras clave: Niños, unidad de cuidados intensivos, Jamaica, sepsis

West Indian Med J 2018; 67 (2): 138

\section{INTRODUCTION}

Sepsis afflicts over 30 million individuals worldwide, with an estimated eight million deaths annually in adults (1). Mortality is highest in low- and middleincome countries (LMICs), with five million deaths annually, where poor socio-economic circumstances, limited access to care and non-resilient health systems result in worst outcomes (2). Recent estimates from the United States of America (USA), Canada, Australia, China, India and Europe showed a rising incidence and high mortality rates in children (2-7).
However, sepsis-attributable paediatric mortality data from developing countries are lacking and are usually included with deaths from the major killers of pneumonia, malaria and diarrhoea diseases (8). In countries with considerable resources (USA and the United Kingdom), sepsis is still a major cause of death and is the leading cause of death in intensive care units (ICUs). In resource-limited settings, sepsis also represents a significant public health burden which is bolstered by poorly organized systems of care with many deficiencies (9). 
Cognizant of the enormous burden of paediatric sepsis, efforts are underway to attempt to reduce sepsisattributable mortality through local and global efforts, including the Global Sepsis Alliance (10). In addition, to achieve the United Nations' Sustainable Development Goals, despite resource constraints, concerted effort is needed to address sepsis in LMICs $(11,12)$.

In the Caribbean, there were no national, regional data and few local data on the burden of paediatric sepsis. Cognizant of this deficiency, we conducted this study to provide baseline data on the burden and outcome of paediatric sepsis in a tertiary institution in Jamaica between 2010 and 2014. The intent was to embark on initiatives to build capacity to provide care in order to decrease the burden and improve the outcomes from sepsis in children.

\section{SUBJECTS AND METHODS}

Jamaica is a middle developing island nation in the Caribbean, with a gross domestic product of US $\$ 14.36$ billion (2013 UNICEF estimate). The University Hospital of the West Indies (UHWI), Jamaica, is a tertiary centre that accepts referrals for paediatric malignancies and dialysis across the island and has a special neonatal care unit that manages newborns. Administrative data from 2010 to 2014 were abstracted retrospectively from electronic hospital discharge records of children identified with sepsis, septicaemia and neonatal sepsis, using the World Health Organization's International Classification of Diseases, $10^{\text {th }}$ Revision (ICD-10). The abstraction was done electronically with sublime text editing of PDF files using regular expressions by the principal investigator. The data were entered into Microsoft Excel and then imported into Stat a 13 (Stata Corp LLC, Lakeway Drive College Station, Texas, USA). Outcome data were acquired from the administrative database of the UHWI. Data were missing in less than $0.2 \%$ of the cases.

\section{Statistical analysis}

Descriptive analysis of the demographics and outcomes of children aged 0-16 years at the time of hospital admission was reported. Crude mortality rates were calculated using the data obtained. The period prevalence of sepsis among children at the UHWI and the mortality risk were calculated.

\section{RESULTS}

A total of 7011 children aged between 0 and 16 years were admitted between January 2010 and December
2014. There were 801 hospitalizations in 782 children admitted for paediatric sepsis with a male to female ratio of 1.27 to 1 . Most (86\%) were neonates. The median length of hospitalization was 10 days (range: 0-366 days; interquartile range (IQR): 7-19 days). The rate of sepsis was low in older children and adolescents.

The case fatality rate in all children admitted with sepsis as a diagnosis was $13 \%$. The sex-specific mortality rate was higher in females than males (Table).

Table: Grouped case fatality rates of participants, 2010-14

\begin{tabular}{|c|c|c|}
\hline & Case fatality rate & Total \\
\hline \multicolumn{3}{|l|}{ Age } \\
\hline Neonatal (0-28 days) & $70(10 \%)$ & 692 \\
\hline Post-neonatal (28 days-1 year) & $17(15 \%)$ & 114 \\
\hline Preschool (1-4 years) & $2(20 \%)$ & 10 \\
\hline School age (4-12 years) & $4(7.1 \%)$ & 56 \\
\hline Adolescent (12-16 years) & $11(36.7 \%)$ & 30 \\
\hline \multicolumn{3}{|l|}{ Gender } \\
\hline Male & $43(9.6 \%)$ & 449 \\
\hline Female & $45(13 \%)$ & 347 \\
\hline
\end{tabular}

Among children with sepsis, $86 \%(\mathrm{n}=691)$ were neonates. Preterm infants represented $36.2 \%(n=250)$ of the septic neonates. The case fatality rate for sepsis among neonates was $10.1 \%(\mathrm{n}=70)$. The case fatality rate was $18.4 \%(n=46 / 250)$ among preterm neonates and $6 \%(n=26 / 434)$ in term neonates with sepsis. There was no change in the annual crude mortality rate over the five-year period (Figure).

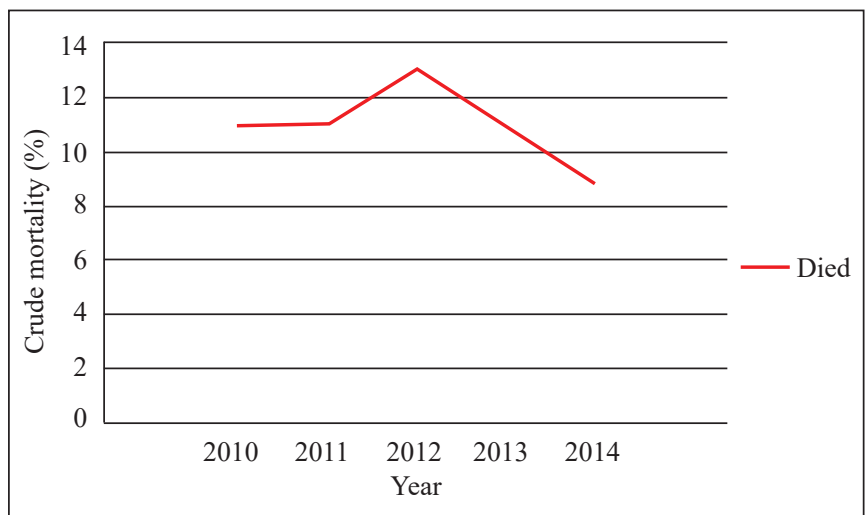

Figure: Crude paediatric sepsis mortality rates, 2010-14.

The case fatality rate in children with sepsis above the age of two years was $25.5 \%(n=12 / 47)$. The annual case fatality rate for paediatric sepsis ranged from $9 \%$ to $11 \%$ with no statistically significant difference across the years. The crude mortality rate for sepsis was 12 per 1000 paediatric hospitalizations. 
The median length of hospital stays for neonates was 10 days with an IQR of 7-19 days. The median length of stays for infants and children beyond the neonatal period was 8 days with an IQR of 4-18 days. The median length of hospital stay of in-patients who survived the median length of stay was similar to that of those who died, but the IQR was smaller, at 4.5-16.5 days. Only $10 \%$ of deaths occurred on the first day after hospitalization. Admissions for sepsis during the period represented 14202 days of hospitalization.

\section{DISCUSSION}

This was a preliminary report of paediatric sepsis in a tertiary institution in Jamaica. Jamaica represents a middle-income country. This pattern of sepsis may be similar to that of a developed country since the majority of paediatric sepsis cases occur in neonates and decrease as the children age. In a retrospective review by Bell et $a l$, the incidence of neonatal sepsis at the UHWI was 6.7 per 1000 live births (13). This study cannot be compared with the current study because a restricted definition of culture-proven bacterial sepsis was used in the former, as compared to the latter where the ICD-10 formed the basis of the inclusion criteria (12).

The present study showed a high mortality rate of $10 \%$ in children with sepsis aged over one year. This was higher than that reported from developed countries. Wang et al reported a $3.5 \%$ overall case fatality rate for sepsis and $34.6 \%(n=53 / 153)$ for severe sepsis in paediatrics cases (aged 28 days to 15 years) seen in 2010-11 in China (5). The rate was also higher than the $5.3 \%$ crude in-hospital mortality among 20130 admitted children aged 0-17 years in Canada (3). Mortality rates vary widely depending on the socio-economic context and resources and are usually higher in LMICs. The sepsis-attributable mortality rate was $5.6 \%$ and septic shock, $17 \%$, in children admitted to ICUs in Australia (4). In contrast, Orrett and Changoor reported a $15 \%$ crude mortality among patients with bacteraemia from Trinidad (14), and Khan et al reported a crude mortality rate of $24 \%$ in hospitalized patients in paediatric ICUs from Pakistan (15).

Sepsis was more common among males, but the proportion of males with sepsis was less than male hospitalizations. This may be due to a higher propensity of males to be injured and the general higher susceptibility of males to illness in childhood. Death rates were similar in both genders.

This study identified preterm neonates as the highest risk group for sepsis-related mortality, especially the extreme preterm with a decline in the total number of deaths among children beyond the neonatal period. Trotman et al had previously reported a prevalence of high mortality (15\%) among preterm neonates with bacteraemia at the UHWI (16). Ali reported a high mortality $(27 \%)$ of term and preterm patients with bacteraemia from Mount Hope Women's Hospital, Trinidad and Tobago (17). The recognition of the high rate of sepsis was comparable to other studies from developing countries (18). Because of their immature immune system (eg diminished capacity to produce immunoglobulins), prolonged hospitalization, increased risk of hospitalacquired infection and thin skin, preterm infants are susceptible to sepsis. In evaluating deaths within the first day or less of presentation for sepsis, it is instructive that the majority of the deaths in this study occurred after the first day, unlike a report by Cvetkovic et al that showed that the majority of paediatric sepsis mortality cases in paediatric ICUs occurred within the first 24 hours (19). This is surprising in that in most instances, critically ill children in LMICs arrive late to definitive care and suffer early demise. Cvetkovic et al reported their experience from the United Kingdom, and thus the type of infections, severities of illness and outcomes were likely to be different. However, the onset of death which occurred earlier than that reported in this study warrants further exploration. Others have shown that earlier onset of therapy for sepsis contributed to better sepsis outcomes with a reduction in mortality rates (20-22). Therefore, this study suggests that if aggressive early intervention is instituted in our hospitalized population with sepsis, we may be able to decrease mortality in most patients.

The number of children admitted for sepsis was high, and there was associated prolonged hospitalization in some cases. Asthma represented the single most common $(10 \%)$ chronic paediatric disease for which children were admitted to the UWHI. The median length of hospital stays was $66 \%$ longer in patients with sepsis when compared with children admitted with asthma. This is certainly suggestive of sepsis leading to increased consumption of scare resources locally.

Sepsis-attributable morbidity is also of significant concern. Globally, 39\% of children who survived severe sepsis experienced deterioration of function at 28 days (23). In LMICs, because of the high burden of mortality and the related social and economic context of these settings, the burden attributed to morbidity has been largely ignored, despite the likely significant contribution from malnutrition. These observations 
present unique opportunities for the development and validation of outcome measures, such as health-related quality of life and functional status measures to better understand and develop interventions for postdischarge morbidity in these complex settings (24). Thus, this study which addressed only mortality did not address the impact of sepsis on children who survived hospitalization.

Another area worthy of investigation is post-discharge mortality after hospitalization. A systematic review of 13 studies conducted in LMICs showed a consistent trend of post-discharge mortality similar to, and in some cases exceeding, in-hospital mortality (24). Post-discharge mortality was most common in the first weeks to months following discharge and in children who were young, malnourished, previously admitted, infected with HIV and those with pneumonia. These observations suggest opportunities for early and inexpensive interventions to decrease the burden of morbidity and mortality in these contexts. Thus, efforts to understand and implement simple measures to decrease or avert post-discharge morbidity are important.

Sepsis is classified into four categories by the international consensus definition for paediatric sepsis: sepsis, severe sepsis, sepsis with multiple organ dysfunction and septic shock (25). Mortality progressively worsens by category, with septic shock having mortality as high as $50 \%$ in low-income countries. However, the consensus definition relies on laboratory data that may not be available in LMICs. In addition, the use of administrative data, as in this study, is associated with selection and reporting bias because of the challenges in disaggregating sepsis from severe sepsis due to the use of the ICD-10 code $(26,27)$. Because administrative data were used in this study, the definition of sepsis may not necessarily meet the consensus criteria; hence, comparability with studies that used the consensus definition may be limited. Future validation studies will be needed to identify ascertainment errors and decrease the risk of differential misclassification.

Given the retrospective nature of this study, sepsis was probably under-diagnosed and hence not reflected in the ICD-10 coding used in the UHWI database. Thus, the sepsis rate might indeed have been understated by a large factor. Preterm birth is a major confounder for sepsis in the neonatal age group, and sensitivity analysis done showed a marginal reduction when patients with extreme prematurity were excluded from analysis. In this study, the total length of hospital stays of patients with sepsis may have been overstated since some patients might have stayed because of reasons other than sepsis.

\section{CONCLUSION}

With the preliminary data that this study has provided on the burden of sepsis in a tertiary centre over a five-year period, we will now conduct further prospective studies. Cost-effective therapeutic intervention in LMICs that may reduce mortality is the goal.

\section{REFERENCES}

1. Fleischmann C, Scherag A, Adhikari NK, Hartog CS, Tsaganos T, Schlattmann $\mathrm{P}$ et al. Assessment of global incidence and mortality of hospital-treated sepsis. Current estimates and limitations. Am J Respir Crit Care Med 2016; 193: 259-72.

2. Ruth A, McCracken CE, Fortenberry JD, Hall M, Simon HK, Hebbar KB. Pediatric severe sepsis: current trends and outcomes from the Pediatric Health Information Systems database. Pediatr Crit Care Med 2014; 15: 828-38.

3. Thompson GC, Kissoon N. Sepsis in Canadian children: a national analysis using administrative data. Clin Epidemiol 2014; 6: 461-9.

4. Schlapbach LJ, Straney L, Alexander J, MacLaren G, Festa M, Schibler A et al. Mortality related to invasive infections, sepsis, and septic shock in critically ill children in Australia and New Zealand, 2002-13: a multicentre retrospective cohort study. Lancet Infect Dis 2015; 15: 46-54.

5. Wang Y, Sun B, Yue H, Lin X, Li B, Yang X et al. An epidemiologic survey of pediatric sepsis in regional hospitals in China. Pediatr Crit Care Med 2014; 15: 814-20.

6. Ganjoo S, Ahmad K, Qureshi UA, Mir ZH. Clinical epidemiology of SIRS and sepsis in newly admitted children. Indian J Pediatr 2015; 82: 698-702.

7. Folgori L, Livadiotti S, Carletti M, Bielicki J, Pontrelli G, Ciofi Degli Atti ML et al. Epidemiology and clinical outcomes of multidrugresistant, gram-negative bloodstream infections in a European tertiary pediatric hospital during a 12-month period. Pediatr Infect Dis J 2014; 33: 929-32.

8. Kissoon N, Uyeki TM. Sepsis and the global burden of disease in children. JAMA pediatrics 2016; 170: 107-8.

9. Kang KT, Chandler HK, Espinosa V, Kissoon N. Systems for paediatric sepsis: a global survey. West Indian Med J 2014; 63: 703-10.

10. Reinhart K, Daniels R, Kissoon N, O’Brien J, Machado FR, Jimenez E. The burden of sepsis - a call to action in support of World Sepsis Day 2013. J Crit Care 2013; 28: 526-8.

11. Kissoon N, Dugani S, Bhutta ZA. Maternal and child health: gains, but a long journey ahead. CMAJ 2015; 187: E471-2.

12. Hartman ME, Linde-Zwirble WT, Angus DC, Watson RS. Trends in the epidemiology of pediatric severe sepsis. Pediatr Crit Care Med 2013; 14: 686-93.

13. Bell Y, Barton M, Thame M, Nicholson A, Trotman H. Neonatal sepsis in Jamaican neonates. Ann Trop Paediatr 2005; 25: 293-6.

14. Orrett FA, Changoor E. Bacteremia in children at a regional hospital in Trinidad. Int J Infect Dis 2007; 11: 145-51.

15. Khan MR, Maheshwari PK, Masood K, Qamar FN, Haque AU. Epidemiology and outcome of sepsis in a tertiary care PICU of Pakistan. Indian J Pediatr 2012; 79: 1454-8.

16. Trotman H, Bell Y, Thame M, Nicholson AM, Barton M. Predictors of poor outcome in neonates with bacterial sepsis admitted to the University Hospital of the West Indies. West Indian Med J 2006; 55: 80-4.

17. Ali Z. Neonatal bacterial septicaemia at the Mount Hope Women's Hospital, Trinidad. Ann Trop Paediatr 2004; 24: 41-4.

18. Kissoon N, Carcillo JA. Correpsondence: mortality after fluid bolus in African children with sepsis. N Engl J Med 2011; 365: 1348-53, reply to the editor. Available at: www.nejm.org/doi/full/10.1056/ NEJMc1108712. 
19. Cvetkovic M, Lutman D, Ramnarayan P, Pathan N, Inwald DP, Peters MJ. Timing of death in children referred for intensive care with severe sepsis: implications for interventional studies. Pediatr Crit Care Med 2015; 16: 410-7.

20. Cruz AT, Perry AM, Williams EA, Graf JM, Wuestner ER, Patel B. Implementation of goal-directed therapy for children with suspected sepsis in the emergency department. Pediatrics 2011; 127: e758-66.

21. Paul R, Melendez E, Stack A, Capraro A, Monuteaux M, Neuman MI. Improving adherence to PALS septic shock guidelines. Pediatrics 2014; 133: e1358-66.

22. Paul R, Neuman MI, Monuteaux MC, Melendez E. Adherence to PALS sepsis guidelines and hospital length of stay. Pediatrics 2012; 130: e273-80.

23. Farris RW, Weiss NS, Zimmerman JJ. Functional outcomes in pediatric severe sepsis: further analysis of the researching severe sepsis and organ dysfunction in children: a global perspective trial. Pediatr Crit Car Med 2013; 14: 835-42.

24. Wiens MO, Pawluk S, Kissoon N, Kumbakumba E, Ansermino JM, Singer J et al. Pediatric post-discharge mortality in resource poor countries: a systematic review. PLoS One 2013; 8: e66698.

25. Goldstein B, Giroir B, Randolph A. International pediatric sepsis consensus conference: definitions for sepsis and organ dysfunction in pediatrics. Pediatr Crit Care Med 2005; 6: 2-8.

26. Balamuth F, Weiss SL, Hall M, Neuman MI, Scott H, Brady PW et al. Identifying pediatric severe sepsis and septic shock: accuracy of diagnosis codes. J Pediatr 2015; 167: 1295-300.e4.

27. Scott HF, Paul R, Balamuth F. The spectrum of pediatric sepsis: "septicemia" misses severe cases. Ann Emerg Med 2015; 66: 685-6. 